\title{
PSYCHE
}

\begin{tabular}{lll}
\hline Vol. 60 & March, 1953 & No. 1 \\
\hline
\end{tabular}

\section{THREE NEW ANTS RELATED TO STRUMIGENYS LOUISIANAE ROGER ${ }^{1}$}

\author{
By William L. Brown, JR. \\ Museum of Comparative Zoology, Harvard University
}

In this time of high printing costs, the difficulty of publishing in one large work the results of my studies on the ant tribe Dacetini has forced me to break up what would otherwise be a revision in one piece into many smaller treatments. It is hoped that, with the publication after each large natural group of a concise key and other general information, the effect of a revision within the same covers will be approached.

Below are described three new species closely related to Strumigenys louisianae Roger, the latter being a common and well-known form ranging from Tennessee and Arizona south through the West Indies and Central America and reaching Bolivia and northern Argentina. S. louisianae has been known under several names in different parts of its range (S. bruchi Forel, S. infidelis Santschi, S. eggersi cubaensis Mann and S. louisianae, various subspecies and varieties), but all of these names are treated as synonyms in an extended discussion of this form at present in press. A distributional peculiarity of $S$. louisianae seems to be pointed up by the lack of records from the rainforest areas of the Amazon-Orinoco Basins and from the extensively collected Panamanian localities centering on Barro Colorado Island.

The descriptions given are all strictly comparative ones

${ }^{1}$ Published with a grant from the Museum of Comparative Zoology at Harvard College. 
drawn against $S$. louisianae. Relationships to other species have not been overlooked, however, as each of the three forms has been compared with all other neotropical species of Strumigenys known to me, both described and undescribed, except $S$. fusca and S. unidentata, two species to be placed among the species inquirendae.

The measurements given are stated in the way standard in recent publications dealing with the dacetine ants. Abbreviations: TL, "total" or synthetic aggregate length of body, including mandibles; $\mathrm{HL}$, maximum measurable length of head proper; ML, exposed length of mandibles; wL, (Weber's) diagonal length of alitrunk, lateral view; CI, cephalic index, or maximum head width expressed as a percentage of HL; MI, mandibulocephalic index, or exposed length of mandibles expressed as a percentage of HL.

Material studied originated from, and is redeposited in, the W. M. Mann and National Museum Collections, United States National Museum (USNM) ; Borgmeier Collection, Petropolis, Brazil; series are also placed by exchange in the Museum of Comparative Zoology, Harvard University (MCZ). Thanks are due Father Thomáz Borgmeier, Dr. W. M. Mann and Dr. M. R. Smith for the privilege of examining the above-mentioned series.

All three species, like $S$. louisianae, belong to the nominate subgenus of Strumigenys.

\section{Strumigenys clasmospongia new species}

Holotype worker: TL $2.57 \mathrm{~mm}$., HL $0.60 \mathrm{~mm}$., ML 0.39 mm., WL $0.58 \mathrm{~mm}$., CI 74, MI 65 .

Similar to S. louisianae, but differing in its larger, distinctly more slender body and relatively much longer mandibles, and also in the following details:

(1) Promesonotum with a fine but distinct median longitudinal carinula; lateral carinuliform margins also more distinct, and on each side of the mesonotum forming a low, rounded translucent flange; posterior to each of these flanges is a second smaller, but similar flange at each posterior mesonotal corner. Homologous, but much less distinct flanges may sometimes be seen in $S$. louisianae workers. 
(2) Metanotal groove as distinct as in S. louisianae or slightly more so; posterior mesonotal region a bit more strongly concave and slightly more distinctly constricted.

(3) Petiolar node with a more slender peduncle and the anterior face not so strongly obliquely depressed, the summit rather evenly rounded in profile seen from the side; node only slightly broader than long seen from above.

(4) Dorsum of postpetiole for the most part smooth or nearly so, definitely shining. Gastric dorsum at base with a few feeble costulae, basal tergite only feebly reticulate (covered with a whitish dried film possibly representing a secretion) and with anterior part subopaque, but sides and posterior half moderately but definitely shining. Sculpture over entire body a trifle weaker than in $S$. louisianae.

(5) Pilosity in general a little less abundant and conspicuous; ground pilosity vestigial on alitruncal dorsum. Color ferrugineous.

Holotype (Borgmeier Coll.) taken at Petropolis, State of Rio de Janeiro, Brazil; "gesiebt. Nr. 5884" (T. Borgmeier leg.)

Paratypes: 5 workers (Borgmeier Coll., USNM, MCZ) with data as for holotype. TL 2.54-2.76 mm., HL 0.60-0.65 mm., ML 0.39-0.41 mm., WL 0.58-0.62 mm., CI 71-76, MI 63-66.

Strumigenys producta new species

Holotype worker: TL $2.91 \mathrm{~mm}$., HL $0.65 \mathrm{~mm}$., ML 0.45 mm., WL 0.70 mm., CI 81 , MI 69 .

Very similar to $S$. louisianae, but larger, more slender, and with much longer mandibles. Dentition as in S. louisianae and S. clasmospongia, that is, with a single small preapical tooth and two acute intercalary denticles to the apical fork. Also the following differences from S. louisianae:

(1) Propodeal spines more slender and acute, rather strongly elevated, divergent, longer than the distance between the centers of their bases.

(2) Gastric tergite I with fine basal costulae extending 
$1 / 3$ its length, remainder of its surface only very feebly and superficially reticulate, definitely shining.

(3) Petiole slender, with a long, slender peduncle and subglobose node; posterior spongiform collar vestigial; cariniform.

(4) Ground pilosity of alitrunk reduced and mostly inconspicuous. Color light ferrugineous; appendages, etc. and base of gaster lighter, more yellowish.

Holotype (Mann Coll., USNM) one of a series of $\mathbf{1 5}$ workers in the type series, taken at Rurrenabaque, Rio Beni, Bolivia (W. M. Mann leg.)

Paratypes: (USNM, Coll. Borgmeier, MCZ) Remaining 14 workers of type series, same data. TL 2.85-3.06 mm., HL 0.65-0.70 mm., ML 0.45-0.48 mm., WL 0.69-0.74 mm., CI 78-82, MI 69-70. Color varying from yellowish- to medium-ferrugineous.

\section{Strumigenys mixta new species}

Holotype worker: TL $2.32 \mathrm{~mm}$., HL $0.54 \mathrm{~mm}$., ML 0.31 mm., wL 0.54 mm., CI 83, MI 57.

Differs significantly from S. louisianae only in the following details:

(1) Inner mandibular border with an extra minute denticle slightly basad of the apical third of the ML.

(2) Pilosity decidedly narrower and less conspicuous, especially on the posterior cephalic dorsum. Paired, outstanding hairs, one on each lateral occipital border, each humeral angle and each side of the mesonotum are all finely flagelliform, whereas in S. louisianae, the lateral occipital and mesonotal hairs are stiff and spatulate towards their apices.

(3) Metanotal groove completely or very nearly completely obsolete; in profile from lateral view, the posterior alitruncal dorsum continuous in outline, not interrupted by the notch at the metanotal groove as in S. louisianae.

Color light ferrugineous yellow.

Holotype (USNM) one of $\mathbf{1 5}$ workers taken at Escuintla, Guatemala (W. M. Mann leg.).

Paratypes: 14 workers from type nest series, same data 
as for holotype, and 5 workers from orchid plants (Cattleya bowringeana) shipped from San José, Guatemala and intercepted in U.S. Plant Quarantine at San Francisco, California (SF 20739 Supl.; 46-5348). Deposited in USNM and MCZ. TL 2.14-2.49 mm., HL 0.51-0.59 mm., ML 0.28-0.32, WL 0.51-0.60, CI 80-84, MI 54-60. The Escuintla (type nest) series is made up of mostly smaller, yellow individuals, while that from San José contains workers mostly in the upper part of the size range given and medium ferrugineous or deep burnt-orange in color. Means of dimensions, but not of proportions, differ slightly, but there is also an absolute overlap. The color difference is not considered taxonomically significant in the face of similar variation seen in many other dacetine species. The name mixta refers to the intermediate characters, seemingly linking $S$. louisianae and S. emeryi Mann, but also distinguishing this species from both. 

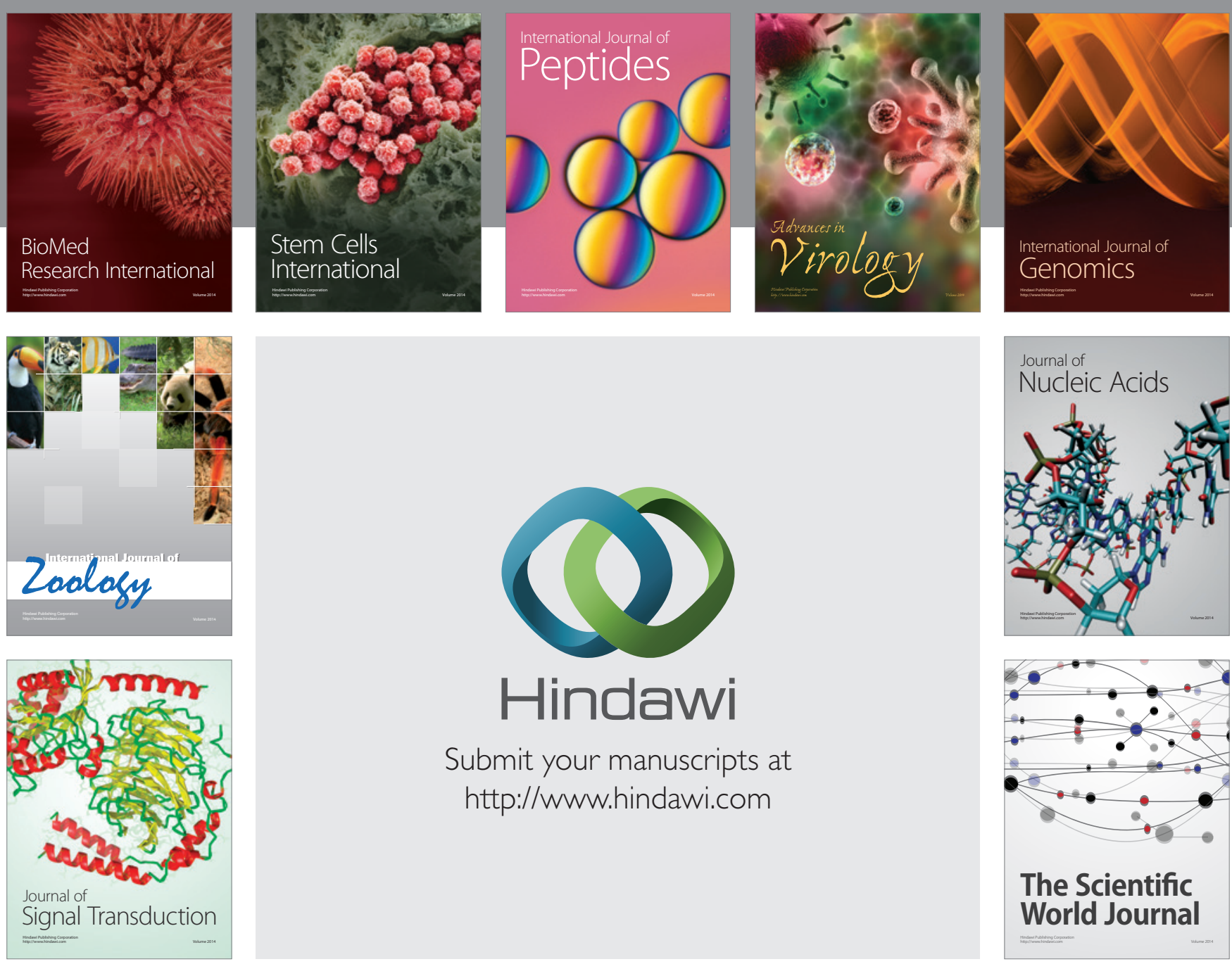

Submit your manuscripts at

http://www.hindawi.com
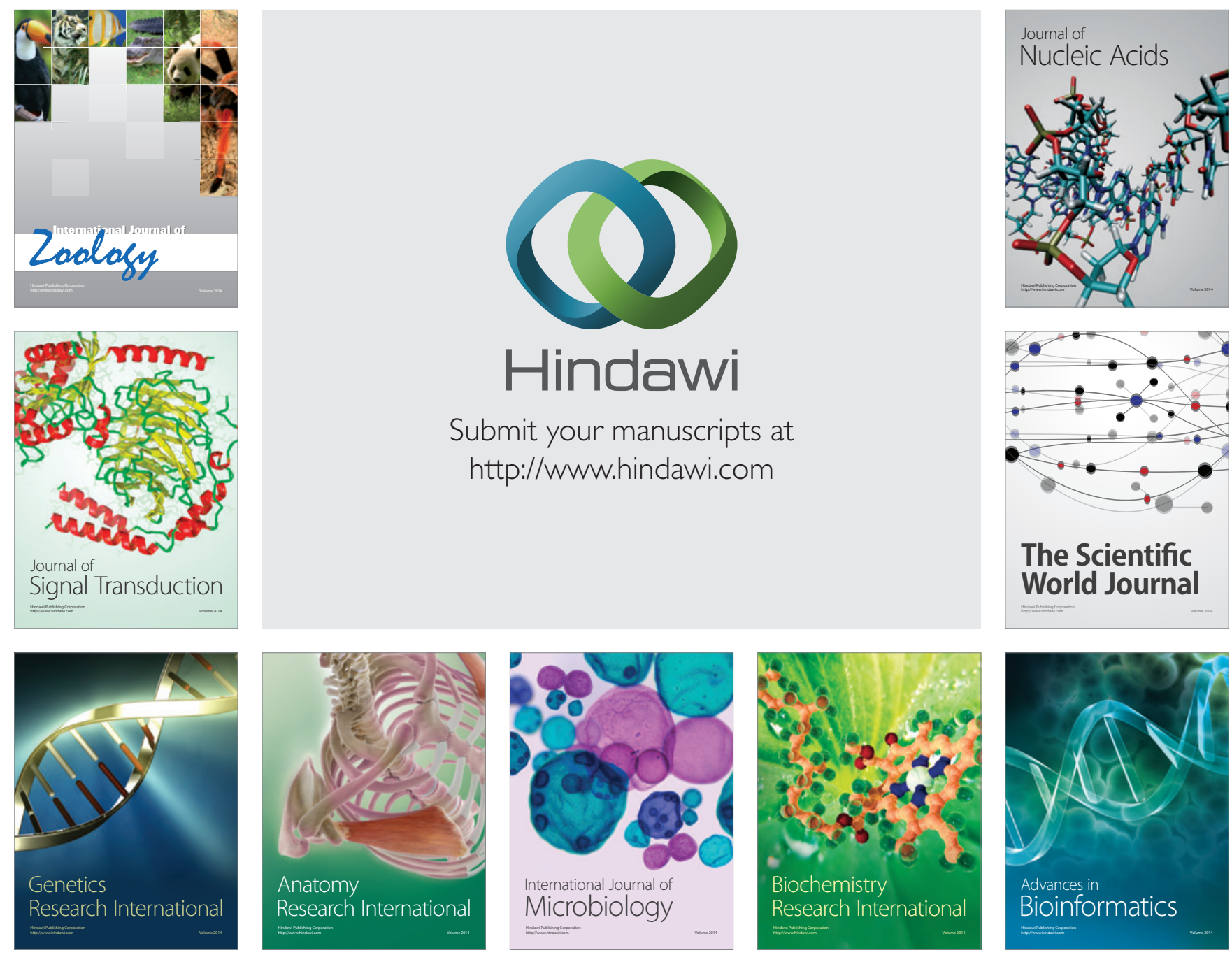

The Scientific World Journal
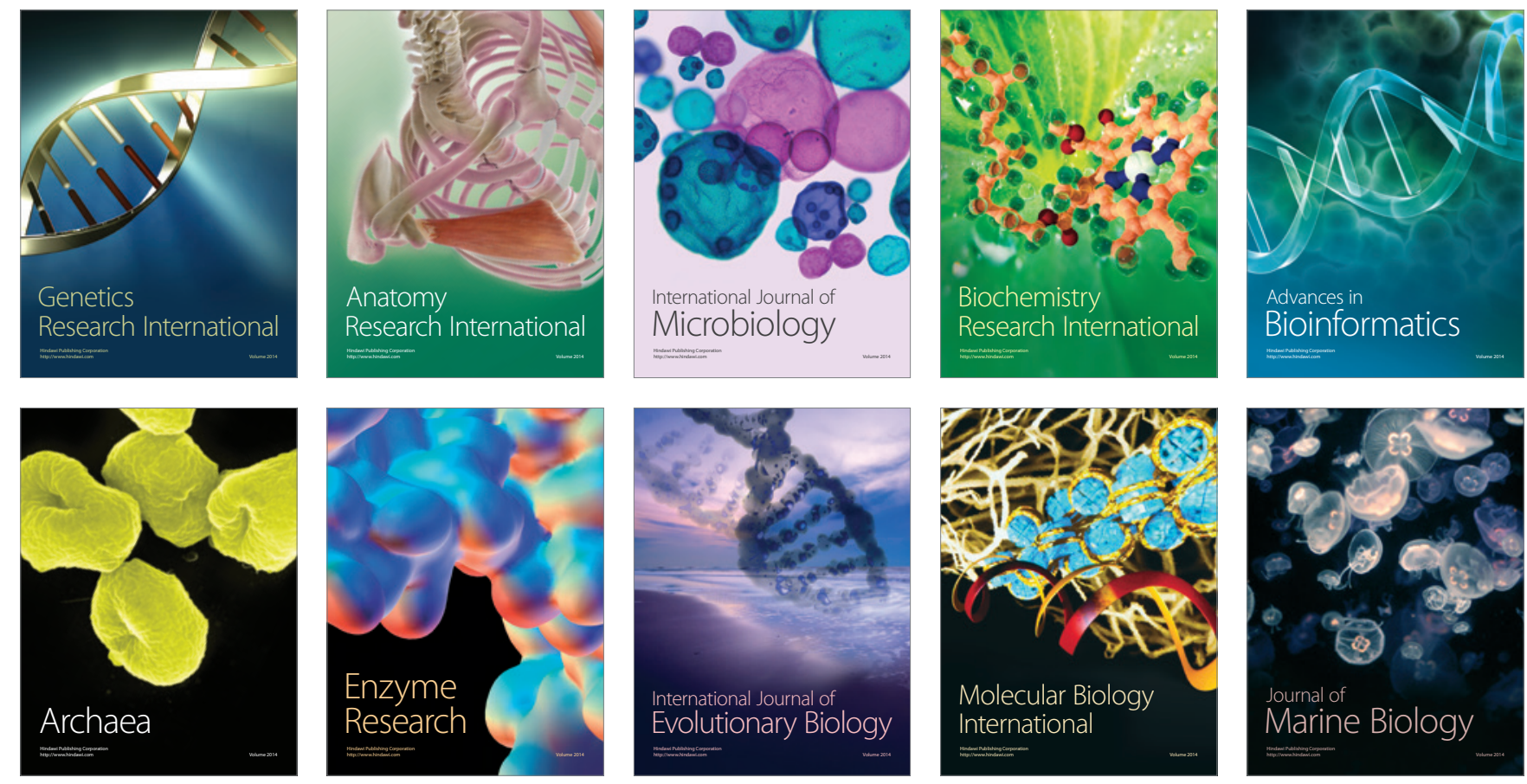